\title{
Penerapan Sistem Informasi Menggunakan Analisis Value Chain Studi Kasus: PT Intan Pariwara Klaten
}

\author{
Nurcahyani Dewi Retnowati \\ Jurusan Teknik Informatika, Sekolah Tinggi Teknologi Adisutjipto \\ Jl. Janti Blok R, Adisutjipto, Yogyakarta 55198, Indonesia \\ Email: cahya_dr@yahoo.com
}

\begin{abstract}
Implementation of Information Systems Using Value Chain Analysis, Case Study: PT Intan Pariwara Klaten. The business activity of PT Intan Pariwara was begun from acceptance of the text, the process editing or the editing of the text, the provisions of all the elements artistic that was needed in the compilation of the book, to handed over CD file the text was ready printed this to the printing house side. The printing house side will afterwards hand over the book that has been printed to the publisher to afterwards be kept in the warehouse to be carried out by the packing and be ready to be distributed to all delegation all over Indonesia. The business strategy for PT Intan Pariwara was to carry out the marketing with marketing powers that had product knowledge that was high enough but also went through an internet media that could increase the company's turnover. The strategy and information technology of the information system for PT Intan Pariwara that is developing the information system that could bridge the publisher with the customer so as to be known by the consumer's wish against products that were produced by the publisher.
\end{abstract}

Keywords: Information System, Value Chain analysis, Business Strategy

\begin{abstract}
Abstrak. Aktivitas bisnis PT Intan Pariwara dimulai dengan penerimaan naskah dari penulis kemuadian dilakukan proses editing atau penyuntingan naskah, penyiapan semua elemen artistic yang dibutuhkan dalam penyusunan buku yang meliputi cover buku dan ilustrasi yang berguna untuk memperjelas materi hingga menyerahkan CD file naskah siap cetak tersebut ke pihak percetakan. Pihak percetakan kemudian akan menyerahkan buku yang sudah dicetak ke penerbit untuk kemudian disimpan di gudang untuk dilakukan pengepakan dan siap didistribusikan ke semua perwakilan di seluruh Indonesia. Strategi bisnis PT Intan Pariwara antara lain strategi pengembangan pemasaran melalui internet dan strategi peningkatan hubungannya dengan pelanggan melalui sistem CRM. Sistem atau aplikasi yang perlu dikembangkan antara lain situs interaktif dan CRM (Customer Relationship Management)
\end{abstract}

Kata Kunci: Sistem Informasi, Analisis Value Chain (Rantai Nilai), Strategi Bisnis

\section{Pendahuluan}

Pada era globalisasi sekarang ini, sebuah perusahaan dalam operasionalisasinya membutuhkan suatu strategi bisnis yang dapat mendukung aktivitasnya sehingga dapat meningkatkan pendapatan bagi perusahaan maupun dapat memberikan kekuatan bagi perusahaan dalam persaingannya dengan perusahaan lain yang sejenis. PT Intan Pariwara yang bergerak dalam bidang penerbitan dan percetakan buku pelajaran dan buku umum berskala 
nasional membutuhkan suatu strategi baik itu strategi bisnis maupun strategi sistem informasi untuk mendukung aktivitasnya yang dipetakan dalam analisis value chain (rantai nilai).

\section{Tinjauan Pustaka}

\subsection{Konsep Dasar Sistem Informasi}

Sebuah sistem informasi merupakan kumpulan dari perangkat keras dan perangkat lunak komputer serta perangkat manusia yang akan mengolah data menggunakan perangkat keras dan perangkat lunak tersebut (Kristanto, 2003). Telah diketahui bahwa informasi merupakan hal yang sangat penting bagi manajemen di dalam pengambilan keputusan.

Sistem informasi adalah suatu sistem didalam suatu organisasi yang mempertemukan kebutuhan pengolahan transaksi harian yang mendukung fungsi operasi organisasi yang bersifat manajerial dengan kegiatan strategi dari suatu organisasi untuk dapat menyediakan kepada pihak luar tertentu dengan laporan-laporan yang diperlukan (Sutabri, 2004).

Definisi lain sistem informasi (Kristanto, 2003) adalah sebagai berikut: (1) Suatu sistem yang dibuat oleh manusia yang terdiri dari komponen-komponen dalam organisasi untuk mencapai suatu tujuan yaitu menyajikan informasi. (2) Sekumpulan prosedur organisasi yang pada saat dilaksanakan akan memberikan informasi bagi pengambil keputusan dan / atau untuk mengndalikan organisasi.

\subsection{Manfaat Sistem Informasi}

Adapun manfaat dari sistem informasi, menurut Kristanto (2003), adalah sebagai berikut: (1) Organisasi menggunakan sistem informasi untuk mengolah transaksi-transaksi, mengurangi biaya dan menghasilkan pendapatan sebagai salah satu produk atau pelayanan mereka. (2) Bank menggunakan sistem informasi untuk mengolah cek-cek nasabah dan membuat berbagai laporan rekening koran dan transaksi yang terjadi. (3) Perusahaan menggunakan sistem informasi untuk mempertahankan persediaan pada tingkat paling rendah agar konsisten dengan jenis barang yang tersedia.

\subsection{Hubungan Antara Strategi Bisnis, Sistem Informasi Dan teknologi Informasi}

Strategis bisnis yang diterapkan oleh sebuah perusahaan tidak dapat dilepaskan begitu saja dari strategi sistem informasi dan strategi teknologi informasi karena dengan adanya perkembangan/kemajuan sistem informasi dan teknologi informasi maka perusahaan tersebut dapat memanfaatkannya untuk mendukung strategi bisnisnya. Hubungan antara strategi bisnis, sistem informasi dan teknologi informasi dapat dijelaskan pada gambar 1. 


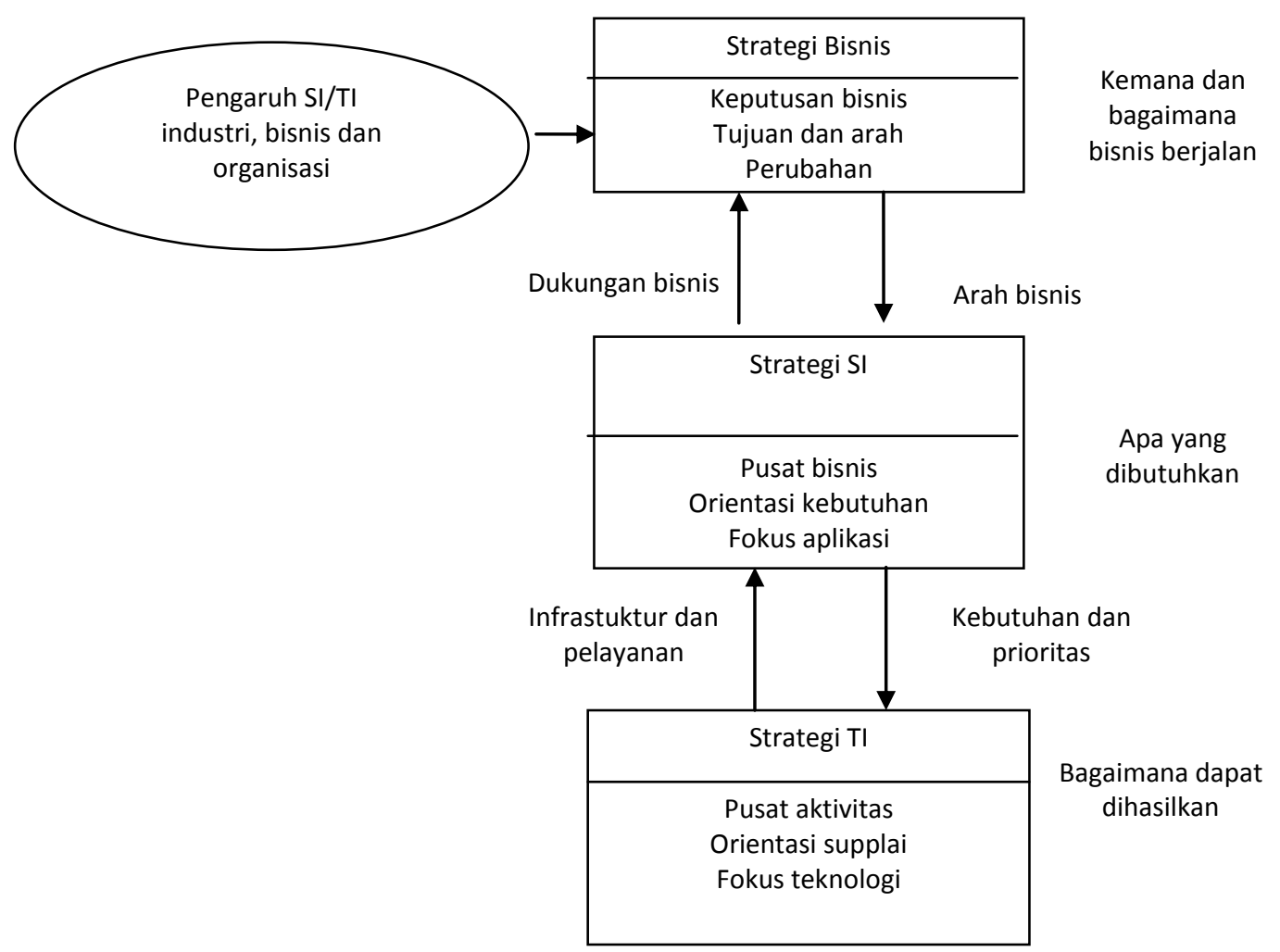

Gambar 1. Hubungan Antara Strategi Bisnis, SI dan TI (Sumber : Ward, 2002)

\subsection{Model Rantai Nilai (Value Chain)}

Porter (1985) dalam buku Jogiyanto (2005), membagi aktivitas di dalam perusahaan menjadi sembilan aktivitas yang dikelompokkan menjadi dua aktivitas besar, yaitu empat aktivitas pendukung dan lima aktivitas utama, seperti terlihat pada gambar 2 .

\begin{tabular}{|c|c|c|c|c|c|}
\hline \multirow[t]{6}{*}{$\begin{array}{c}\text { Aktivitas } \\
\text { Pendukung }\end{array}$} & \multicolumn{5}{|c|}{$\begin{array}{l}\text { Infrastruktur Perusahaan } \\
\text { (Manajemen umum, akuntansi, keuangan dan perencanaan strategis) }\end{array}$} \\
\hline & \multicolumn{5}{|c|}{$\begin{array}{l}\text { Manajemen Sumber Daya Manusia } \\
\text { (Perekrutan, pelatihan, dan pengembangan) }\end{array}$} \\
\hline & \multicolumn{5}{|c|}{$\begin{array}{c}\text { Perkembangan Teknologi } \\
\text { (R\&D, perbaikan produk dan proses) }\end{array}$} \\
\hline & \multicolumn{5}{|c|}{$\begin{array}{c}\text { Pembelian } \\
\text { (Pembelian bahan mentah, mesin dan peralatan) }\end{array}$} \\
\hline & $\begin{array}{l}\text { Inbound Logistics } \\
\text { (Penanganan } \\
\text { bahan mentah dan } \\
\text { pergudangan) }\end{array}$ & Operasi & $\begin{array}{c}\text { Outbound } \\
\text { Logistics } \\
\text { (Penggudangan } \\
\text { dan } \\
\text { Distribusi harga, } \\
\text { Produk jadi) }\end{array}$ & $\begin{array}{c}\text { Pemasaran Dan } \\
\text { Penjualan } \\
\text { (Iklan promosi) }\end{array}$ & $\begin{array}{l}\text { Pembelian } \\
\text { (Bahan } \\
\text { mentah, } \\
\text { mesin, } \\
\text { dan } \\
\text { peralatan) }\end{array}$ \\
\hline & \multicolumn{5}{|c|}{ Aktivitas Utama } \\
\hline
\end{tabular}

Gambar 2. Model rantai nilai oleh Porter (Sumber : Hunger, 2003) 
Empat aktivitas pendukung yaitu infrastruktur perusahaan (management and administrative services yaitu manajemen, akuntansi, keuangan, dan sebagainya), manajemen sumberdaya manusia (human resource manajement seperti penerimaan, pelatihan dan pengembangan sumberdaya manusia), pengembangan teknologi (technology development seperti R\&D, peningkatan kualitas produk dan proses), dan pengadaan barang (procurement).

Porter mengidentifikasi lima kegiatan utama yang biasanya terjadi di setiap bisnis: (1) inbound logistics bahan mentah; (2) operasi; (3) outbound logistics barang jadi; (4) pemasaran dan penjualan, dan (5) layanan konsumen (Hunger, 2003). Porter menjelaskan bahwa untuk mencapai keuntungan kompetisi, kesembilan kegiatan-kegiatan tersebut harus ditingkatkan nilainya, yaitu harus efisien dan efektif. Nilai di tiap kegiatan akan dibawa kegiatan lainnya dan akan menambah nilai di kegiatan berikutnya dan seterusnya, sehingga akhir dari seluruh kegiatan akan sangat bernilai.

\subsection{Matriks McFarlan}

Matriks McFarlan (Ward, 2002) digunakan untuk menyusun portofolio aplikasi berdasarkan prioritas dari masing-masing aplikasi tersebut, yang kemudian menjadi bahan pertimbangan dalam perencanaan pengembangan aplikasi-aplikasi tersebut. McFarlan mengembangkan model portofolio aplikasi dengan melihat kontribusi aplikasi SI/TI terhadap organisasi saat ini dan di masa depan. Matriks McFarlan terdiri atas empat kuadran: (1) Strategic, aplikasi ini mempunyai posisi yang kritikal dalam mewujudkan strategi perusahaan di masa depan. (2) High Potential, aplikasi ini suatu saat harus dimiliki untuk mencapai kesukses an bagi perusahaan. (3) Support, aplikasi ini bersifat pendukung tapi tidak kritikal dalam mencapai kesuksesan. (4) Key operational, aplikasi tersebut harus ada dan perusahaan pada saat ini tergantung pada aplikasi tersebut untuk mencapai sukses.

\section{Metodologi Penelitian}

Metode penelitian yang digunakan adalah sebagai berikut: (1) Analisis value chain. Analisis value chain bertujuan untuk mengetahui konteks bisnis dari PT Intan Pariwara. (2) Analisis Lingkungan SI. Tahapan ini bertujuan untuk menyusun daftar aplikasi yang ada untuk dipetakan ke dalam portofolio akhir dan juga untuk membantu dalam menentukan aplikasi mana yang mendapat prioritas utama dalam pengembangan. Metode yang digunakan dalam tahapan ini adalah penyusunan portofolio aplikasi yang diturunkan dari matriks McFarlan.

\section{Pengujian dan Pembahasan}

\subsection{Analisis Value Chain (Proses Bisnis)}

Rangkaian aktivitas inti PT Intan Pariwara dapat digambarkan pada analisis Value Chain yang terlihat pada gambar 3. Aktivitas bisnis dimulai dengan penerimaan naskah dari penulis kemuadian dilakukan proses editing atau penyuntingan naskah yang meliputi penyesuaian naskah dengan kurikulum yang berlaku, memperbaiki tata bahasa, meningkatkan bobot produksi dan meng-up date informasi yang disesuaikan dengan perkembangan terbaru. Bagian produksilah yang menetukan apakah naskah tersebut layak terbit atau tidak.

Proses selanjutnya, bagian desain akan menyiapkan semua elemen artistic yang dibutuhkan dalam penyusunan buku yang meliputi cover buku dan ilustrasi yang berguna untuk memperjelas materi. Pada saat yang bersamaan, bagian lay out atau tata letak akan menyusun naskah buku dalam format buku sebenarnya. Yang dikerjakan oleh bagian tata letak adalah mengetik naskah, memasang ilustrasi untuk buku (gambar atau foto), menyediakan print out dummy buku siap cetak dan memasukkan dalam CD file naskah siap cetak. Proses selanjutnya adalah menyerahkan CD file naskah siap cetak tersebut ke pihak percetakan. Setiap tahapan produksi mendapat pengawasan langsung dari Publishing Editor maupun Manajer Produksi. 


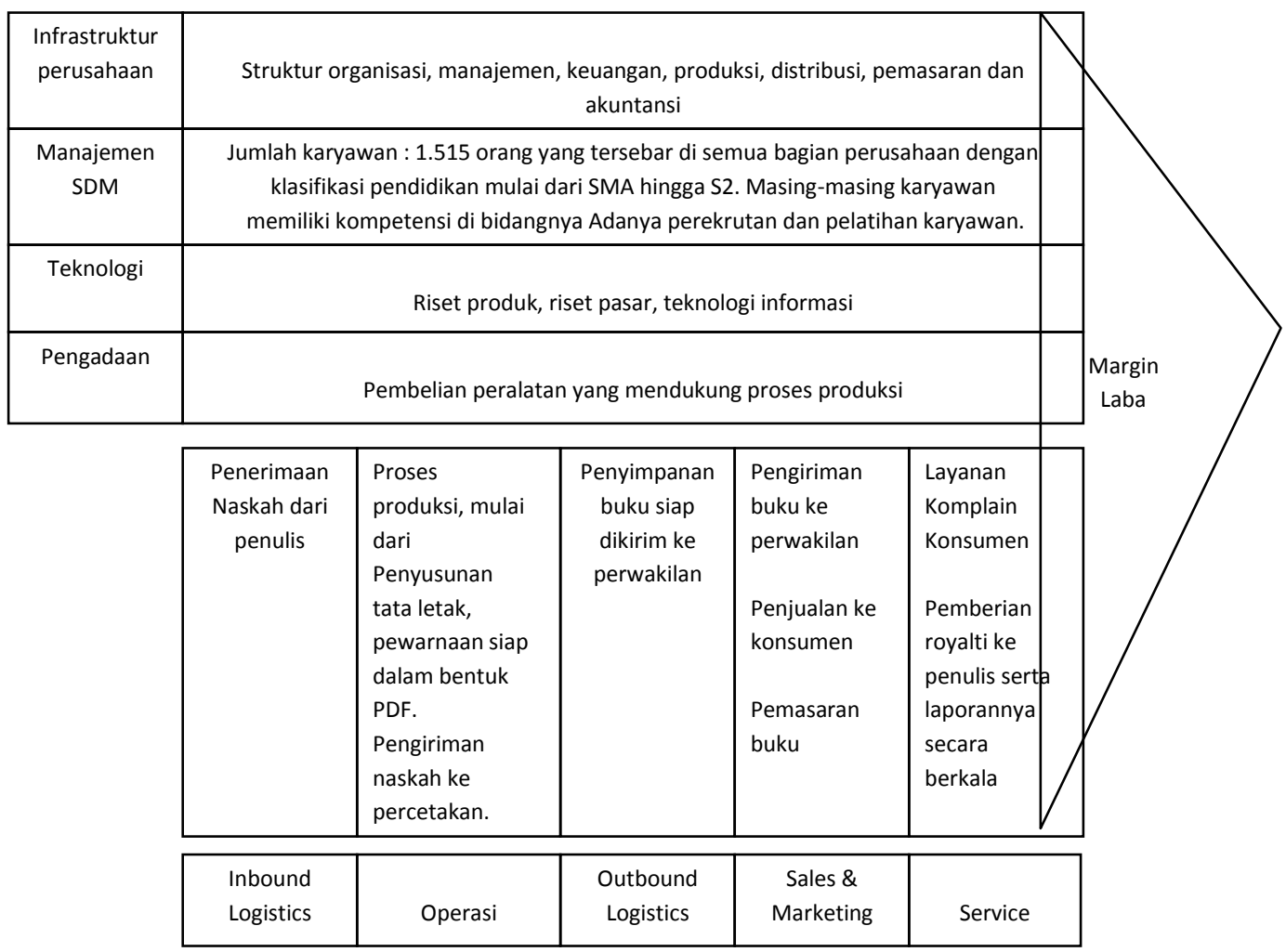

Gambar 3. Proses Bisnis PT Intan Pariwara

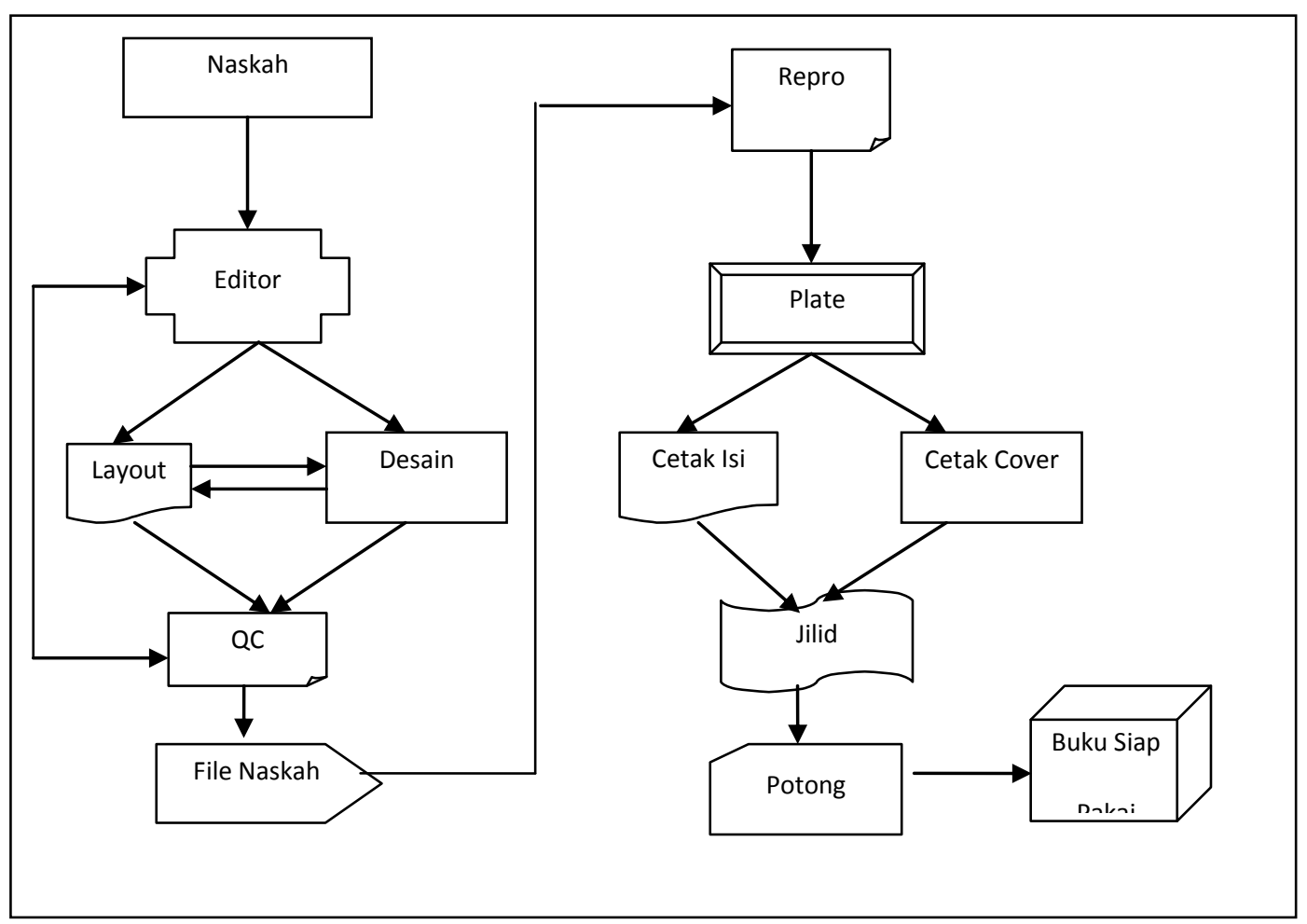

Gambar 4. Proses Pembuatan Buku

Pihak percetakan kemudian akan menyerahkan buku yang sudah dicetak ke penerbit untuk kemudian disimpan di gudang untuk dilakukan pengepakan dan siap didistribusikan ke semua perwakilan di seluruh Indonesia. 
Untuk konsumen, penerbit menyediakan layanan komplain konsumen melalui nomor telepon maupun alamat email yang dapat digunakan oleh konsumen untuk menyampaikan kritik dan sarannya atas produk buku yang dihasilkan penerbit.

Bisnis inti PT Intan Pariwara adalah pada buku-buku yang diperuntukkan pada tingkat TK, SD, SMP dan SMA. Selain itu juga dihasilkan buku-buku umum. Proses pembuatan buku dapat dilihat pada gambar 4.

\subsection{Perangkat Lunak}

PT Intan Pariwara menggunakan software-software yang dibuat sendiri oleh staf IT-nya untuk mendukung kegiatan operasionalnya. Aplikasi sistem informasi penerbit dikembangkan dengan menggunakan teknologi berbasis Windows dengan menggunakan database Visual Foxpro 7. Aplikasi otomasi kantor digunakan untuk membuat dokumen kegiatan kantor mulai dari surat menyurat, presentasi dan dokumen kantor lainnya. Aplikasi internet menggunakan dua aplikasi yaitu di sisi server dan di sisi client. Aplikasi di server digunakan untuk mendukung fungsi sebagai gateway akses internet dan firewall. Aplikasi yang digunakan adalah MS Proxy. Aplikasi di client menggunakan Internet Explorer yang berfungsi untuk pengaksesan internet.

\subsection{Portofolio Aplikasi Saat Ini}

Aplikasi yang ada pada PT Intan Pariwara dapat dipetakan ke matriks Mc Farlan untuk disusun berdasarkan prioritas dari masing-masing aplikasi tersebut, yang kemudian menjadi bahan pertimbangan dalam perencanaan aplikasi-aplikasi tersebut. Pemetaan aplikasi Mc Farlan pada PT Intan Pariwara dikategorikan menjadi 4 bagian yaitu strategic, high potensial, support dan key operational, yang dapat dilihat pada tabel 1 .

Tabel 1. Portofolio Aplikasi PT Intan Pariwara

\begin{tabular}{ll}
\hline Strategic & High Potential \\
\hline (Belum ada) & (Belum ada) \\
\hline Key Operational & Support \\
\hline Aplikasi Sistem Informasi Penerbit & 1. Otomasi Kantor \\
& 2. Sistem Penggajian, Sistem Informasi Kepegawaian \\
& 3. Aplikasi Internet \\
& 4. Aplikasi Analisis Pasar \\
\hline
\end{tabular}

\subsection{Target Portofolio Aplikasi}

Kebutuhan aplikasi untuk mendukung kegiatan PT Intan Pariwara dapat dilihat pada tabel 2. Targetnya adalah: (1) Strategic. Situs Interaktif : Situs ini akan menjadi alat pemasaran yang cukup efektif dan dapat memudahkan konsumen untuk melihat informasi tentang company profile dari PT Intan Pariwara dan produk-produk yang dihasilkannya. Selain itu juga bisa mempermudah transaksi. (2) Key Operational. Aplikasi Sistem Informasi Penerbit : Aplikasi ini bisa mencatat jumlah produksi buku, jumlah penjualan per buku mencatat royalti penulis dan melihat data jaringan perwakilan. (3) High Potential. Customer Relationship Management. Sistem CRM ini akan lebih mendekatkan penerbit dengan konsumen sehingga loyalitas konsumen akan tetap dapat dipertahankan. (4) Support. (a) Otomasi kantor : Penggunaan aplikasi office untuk mendukung kinerja perusahaan. (b) Sistem Penggajian : Sistem ini dapat mempermudah dalam penggajian karyawan. (c) Sistem Informasi Kepegawaian : Sistem ini dapat mencatat data-data karyawan baik itu karyawan lama maupun karyawan baru, prestasiprestasi yang diperoleh karyawan dan dapat dijadikan pertimbangan untuk kenaikan jabatan karyawan. (d) Aplikasi Internet : Digunakan untuk menunjang aktivitas berinternet. (e) Aplikasi 
Analisis Pasar : Sistem yang dapat menentukan produk mana yang sesuai untuk dilempar ke pasaran dan dapat menentukan kapan waktunya produk tersebut akan dilempar ke pasaran.

Tabel 2. Target Portofolio Aplikasi PT Intan Pariwara

\begin{tabular}{ll}
\hline Strategic & High Potential \\
\hline Situs Interaktif & Customer Relationship Management \\
\hline Key Operational & Support \\
\hline Aplikasi Sistem Informasi Penerbit & 1. Otomasi Kantor \\
& 2. Sistem Penggajian, Sistem Informasi Kepegawaian \\
& 3. Aplikasi Internet \\
& 4. Aplikasi Analisis Pasar \\
\hline
\end{tabular}

\subsection{Strategi Bisnis dan Strategi Sistem Informasi/Teknologi Informasi}

Strategi bisnis untuk PT Intan Pariwara adalah melakukan pemasaran dengan tenagatenaga pemasaran yang memiliki product knowledge yang cukup tinggi dan juga melalui suatu media internet yang dapat meningkatkan omset perusahaan. Strategi sistem informasi dan teknologi informasi untuk PT Intan Pariwara yaitu membangun sistem informasi yang dapat menjembatani penerbit dengan pelanggan sehingga akan diketahui keinginan konsumen terhadap produk-produk yang dihasilkan oleh penerbit. Dari strategi bisnis dan strategi sistem informasi/teknologi informasi di atas dapat disusun portofolio aplikasi yang diperlukan. Keterkaitan antara strategi bisnis, aplikasi dan kebutuhan fungsional dapat dilihat pada tabel 3.

Tabel 3. Keterkaitan Antara Strategi Bisnis, Aplikasi Dan Kebutuhan Fungsional

\begin{tabular}{|c|c|c|}
\hline Strategi Bisnis & Aplikasi & Kebutuhan Fungsional \\
\hline $\begin{array}{l}\text { Mempertahankan loyalitas } \\
\text { pelanggan dengan cara } \\
\text { meningkatkan kualitas } \\
\text { produk dan layanan. }\end{array}$ & $\begin{array}{l}\text { Customer } \\
\text { Relationship } \\
\text { Manajement }\end{array}$ & $\begin{array}{l}\text { Dapat menjadi sumber riset keinginan } \\
\text { konsumen yang dilihat dari historikal } \\
\text { pembelian produk oleh konsumen } \\
\text { Penawaran diskon dan produk. } \\
\text { Pengiriman informasi kepada konsumen } \\
\text { yang berisi tentang informasi produk- } \\
\text { produk baru }\end{array}$ \\
\hline $\begin{array}{l}\text { Memberikan kemudahan } \\
\text { bagi pelanggan untuk } \\
\text { mencari informasi dan } \\
\text { bertransaksi }\end{array}$ & Situs Interaktif & $\begin{array}{l}\text { Sebagai media untuk bertransaksi melalui } \\
\text { internet } \\
\text { Sebagai sumber informasi yang } \\
\text { dibutuhkan oleh konsumen dan calon } \\
\text { konsumen tentang produk-produk PT } \\
\text { Intan Pariwara } \\
\text { Sebagai sarana untuk meningkatkan } \\
\text { keinginan penulis untuk bergabung } \\
\text { dengan PT Intan Pariwara dalam } \\
\text { menghasilkan buku yang berkualitas }\end{array}$ \\
\hline
\end{tabular}

\section{Kesimpulan}

Berdasarkan hasil penelitian dan pembahasan maka dapat disimpulkan: (1) PT Intan Pariwara memerlukan beberapa strategi antara lain strategi pengembangan pemasaran melalui internet dan strategi peningkatan hubungannya dengan pelanggan melalui sistem CRM. (2) Sistem atau aplikasi yang perlu dikembangkan antara lain situs interaktif dan CRM (Customer Relationship Management)

\section{Saran}


Hendaknya penelitian ini dapat diteruskan hingga pada tahap implementasi agar dapat diketahui apakah perencanaan yang telah dilakukan sesuai atau tidak.

\section{Referensi}

Hunger, J. D., Wheelen, T., 2003, Manajemen Strategis, diterjemahkan oleh Julianto Agung S., SE., S. Kom, Penerbit Andi, Yogyakarta.

Jogiyanto, HM., 2005. Sistem Teknologi Informasi. Pendekatan Terintegrasi : Konsep Dasar, Teknologi, Aplikasi, Pengembangan dan Pengelolaan. Edisi II, Penerbit Andi, Yogyakarta.

Kristanto, A., 2003. Perancangan Sistem Informasi Dan Aplikasinya, Penerbit Gava Media, Yogyakarta.

Ward, J., Peppard, J., 2002, Strategic Planning For Information Systems, Third Edition, Cranfield School of Management, Cranfield, Bedfordshire, UK. 